\title{
Is Open-Mindedness Truth-Conducive?
}

\author{
B.J.C. Madison
}

(Forthcoming in Synthese)

Draft Version - Do Not Cite Without Approval

\section{Introduction:}

An intellectual virtue is a human excellence. An intellectual vice is a human defect. Paradigmatic examples of intellectual virtues include: open-mindedness, intellectual courage, and intellectual autonomy (Battaly, 2008, p. 645). Paradigmatic examples of intellectual vices include: dogmatism, carelessness, and gullibility (Cassam, 2016, p. 159). But what makes an intellectual virtue a virtue, and by contrast, an intellectual vice a vice? A straightforward, popular, and influential answer to this question has been given by virtue-reliabilists: a trait is a virtue only insofar as it is conducive to the acquisition of true beliefs, and the avoidance of false beliefs.

Open-mindedness is a paradigm virtue, so one might wonder, is openmindedness truth-conducive? In a recent paper, Jack Kwong explores this question, and defends it against attack. His stated aim is to defend the reliabilist view that a trait is an intellectual virtue to the extent that it reliably leads to truth. In this paper I shall argue that the considerations Kwong offers are good as far as they go, and that they advance the debate by usefully clarifying ways in how best to understand the nature of open-mindedness. But his reflections do not establish the desired 
conclusions that open-mindedness is truth-conducive, and that it is a virtue because it is truth-conducive.

To establish these much stronger conclusions we would need an adequate reply to what I shall call Montmarquet's objection, and in Kwong's paper, no reply is given. I shall also argue that Linda Zagzebski’s reply to Montmarquet's objection, to which Kwong defers, is inadequate. I contend that we are left with the original problem Kwong sought to address: it is contingent if open-mindedness is truthconducive, and if a necessary tie to truth is what makes an intellectual virtue a virtue, then the status of open-mindedness as an intellectual virtue is jeopardised. We either need an adequate reliabilist response to Montmarquet's objection, or else seek alternative accounts of what it is that makes a virtue a virtue. I conclude by briefly outlining some alternatives.

\section{What is Virtue Reliabilism?}

Much of contemporary epistemology has focused on beliefs and their normative properties, such as their justification, warrant, and blame or praiseworthiness, or whether they amount to knowledge. Going against this trend, Ernest Sosa (1980) was an early advocate of expanding our focus beyond doxastic states to the intellectual qualities that constitute human excellences. This movement has become known as virtue epistemology, which is in many ways analogous to virtue ethics. In both virtue epistemology and virtue ethics, the primary objects of evaluation are agents and their (intellectual and moral) character traits, rather than focusing evaluation narrowly on subjects' beliefs and actions.

The heart of virtue-reliabilism is the claim that what makes an intellectual virtue a virtue is that the trait is truth-conducive (e.g. Sosa 1991; 2007). Virtues are 
understood to be stable and robust dispositions to form true beliefs rather than false ones; understanding vices along these lines insists that a trait is an intellectual vice because beliefs formed through their exercise are more likely to be false than true.

Virtue-reliabilists, like Sosa (e.g. Sosa 1991; 2007; and Greco 2010), mainly focus on reliable faculties, skills, or competences, like memory, deduction, and sense perception. But given their liberal understanding of what counts as a virtue, states of character should count too. For example, according to Sosa, anything with a function has virtues, including natural things like eyes, and artifacts, like knives. "[ $[.$. grasping the truth about one's environment [is] among the proper ends of a human being" (Sosa, 1991, p. 271). So the intellectual virtues are those qualities that reliably allow us to attain that end.

While the view does not require truth-conduciveness in all possible worlds, it does require truth-conduciveness in a broad range of conditions that need to be specified $^{1}$. Following Jack Kwong's discussion, the view under consideration here is an analogue of a kind of simple actual world reliabilism. According to such views of epistemic justification, a belief is justified only if it is produced by a reliable belief forming process (e.g. Goldman 1979; 1986). What is relevant is if the belief forming process in that world produces a favorable ratio of true vs. false beliefs.

\footnotetext{
${ }^{1}$ Not all versions of reliabilism, either about epistemic justification or the virtues, require truthconduciveness in the actual world. For example, Sosa holds that the reliability of a cognitive disposition does not require that it attain truths in "highly unusual conditions", just as the reliability of a car does not require that it start when submerged underwater. But for a trait to be a virtue it must be truth-conducive in "normal" circumstances, where reliability is indexed to environments (e.g. Sosa 2007, pp. 83-4). Following Comesana (2002), we can call this a kind of "indexical reliabilism". As Sosa notes, however, normality "is not just statistical normality" (2007, pp.83-4). But saying with any precision just exactly what an epistemically normal environment amounts to is a notoriously difficult problem. This has prompted people to develop alternative accounts of the truth-connection, or like Kwong, to defend actual world reliabilism. Simple actual world reliabilism avoids the problem of specifying what "epistemic normality" amounts to, since the relevant world of assessment is the one where the virtues are exercised, not counterfactual circumstances (normal or otherwise). Actual world reliabilism also has the advantage of giving a clear account of the value of the virtues in instrumental terms, since they are taken to be actually truth-conducive.
} 
Applying a version of that view to the case of the virtues, a trait is a virtue to the extent that it is truth-conducive in the world it is exercised. So in the case of open-mindedness, Kwong writes "By entertaining novel or opposing views in a disinterested way, open-mindedness is supposed to help those who practice it acquire and retain truths, more so than those who do not (e.g. the dogmatic and the credulous)." (Kwong, 2017, pp. 1613-1614) On this sort of reliabilist view, the value of the virtues is straightforward: truth is valuable, and the virtues are instrumentally valuable ways of acquiring truths. Kwong's aim is to defend the tenability of this form of virtue reliabilism, arguing that more complicated forms of virtue reliabilism, or non-reliabilist accounts of the virtues that aim to secure alternative accounts of the truth-connection, are unmotivated.

A reliabilist theory needs to answer the question of where (in which worlds) a trait must be reliable if it is to amount to a virtue. But there also remains the question of what must be reliable. ${ }^{2}$ This issue is familiar from discussions of reliabilist theories of epistemic justification. A token method or way of forming true beliefs is an instance of a more general type of method that can be more or less reliable. However, which types of methods are the relevant ones here? This has become known as the 'generality problem' for reliabilism. ${ }^{3}$

A process type can be individuated more or less finely, with the associated reliability varying widely. For example, when I form a belief about the time on the basis of what my watch says, which method am I using? Is it perception, or visual

\footnotetext{
${ }^{2}$ Scott Sturgeon is a philosopher who distinguishes what he calls the Reliability-Where problem from the Reliability-of-What problem that arises for process reliabilist theories of epistemic justification. Parallel issues arise here for reliabilist accounts of the intellectual virtues. For a discussion of these problems for reliabilism, see Sturgeon (2000), p. 96.

${ }^{3}$ See Conee and Feldman (1998) for an early and influential presentation of this objection against reliabilism. For some recent responses that have tried to solve the generality problem, see for example Heller (1995); Beebe (2004); Comesana (2006); Becker (2008).
} 
perception, or visual perception in good lighting, or visual perception in good lighting when sober, etc.? Some of these methods are far more reliable than others, and yet the charge is that it is difficult (if not impossible) to non-arbitrarily say which method is the one whose reliability is relevant to whether or not epistemic justification obtains, or in this case, to whether or not an intellectual trait amounts to a virtue. The Reliability-Where and the Reliability-of-What problems are formidable challenges that reliabilists (including virtue reliabilists) need to overcome.

With the basic contours of virtue-reliabilism before us, we can now ask: as open-mindedness is a paradigm virtue, is it truth-conducive? In a recent paper, Jack Kwong explores this question, with the aim of defending the reliabilist view that a trait is an intellectual virtue to the extent that it reliably leads to truth (Kwong, 2017). To that end, he responds to two kinds of recent objections, both of which he argues misconstrue the nature of open-mindedness.

Kwong claims that once we have a proper understanding of what openmindedness involves, then it follows that genuine open-mindedness is truth-conducive and its relation to truth is not as contingent as critics have claimed. Kwong boldly concludes that contrary to the challenges he discusses, open-mindedness is truthconducive without qualification, and "as such, it can retain its status as an intellectual virtue based on its connection with truth." (Kwong, p. 1623) It is to this discussion that we now turn.

\section{Kwong's Discussed Challenges to Open-Mindedness and Truth-}

\section{Conduciveness:}

Kwong (2017) discusses two main kinds of objection to the thesis that openmindedness is truth-conducive, most recently advanced by Carter and Gordon (2014). 
Both arguments conclude that whether open-mindedness is truth-conducive is highly contingent, conditional upon things like what a person already believes, or how hospitable the epistemic environment is. For instance, according to Carter and Gordon, if one begins with beliefs that are already true, then being dogmatic will preserve ones true beliefs by protecting them from revision, whereas if one begins with false beliefs, being open-minded opens one to the possibility of acquiring true beliefs, and losing false ones (Carter and Gordon, 2014, p. 208).

Likewise, a putative vice like gullibility might prove to be truth-conducive. For example, a subject might be lucky enough to find themselves in an environment where people always tell the truth, or one is never misled by ones senses, etc. But if the environment is less epistemically friendly, in that one is surrounded by possible sources of error, only then would open-mindedness have the advantage over gullibility by having one be on-guard against the acquisition of false beliefs (Ibid.).

Kwong's main reply to these arguments is a good one: he contends that these arguments rely on impoverished or overly narrow conceptions of what openmindedness consists in. Kwong argues that these objections do not sufficiently distinguish between mere openness, on the one hand, and genuine open-mindedness, on the other. The virtue of open-mindedness properly so-called, Kwong argues, requires not just openness to other beliefs (which might itself be reckless), but must also satisfy additional constraints, such as being aware of ones own biases and prejudices $^{4}$, giving opposing views serious consideration, being sensitive to when a

\footnotetext{
${ }^{4}$ An anonymous referee suggested that Kwong's characterization of the further conditions openmindedness requires might blur the lines between open-mindedness and intellectual humility. Openmindedness is close to, but distinct from, the virtue of intellectual humility. Being aware of one's own biases and prejudices is very similar to the proper attentiveness to, and owning of, one's intellectual limitations, which is the hallmark of Whitcomb et al.'s account of intellectual humility. See Whitcomb et al. (2017). It is an important open question what exactly both open-mindedness and intellectual
} 
person should or should not be open to other views, etc. (Kwong, 2017, pp. 1619-

$1620)^{5}$. Kwong's position is that

the person who gives alternative viewpoints serious consideration is not at risk of losing her true beliefs. Since genuine open-mindedness has a built in mechanism to sift out falsehoods, mistakes, and errors, it is not an obstacle to someone whose aim is to retain truths. [...] suffice it to note that a person is under no obligation whatsoever to open her held true beliefs to scrutiny if she is well-justified in believing them and is correct in thinking that they have not been tainted by bad habits of thought, and / or if she has no reason to think that questioning them is helpful for reaching the truth (Kwong, 2017, p. 1620).

Applying this richer conception of genuine open-mindedness to the arguments above, Kwong argues that open-mindedness, in giving serious consideration to other views which include built-in requirements to monitor for error, is no threat to ones previously held true beliefs, and will aim to prevent the acquisition of false beliefs, by doing things like "weighing the evidence, entertaining alternative viewpoints, following an argument to its conclusion, etc.” (Kwong, 2017, p. 1621) Kwong's claim is that genuine open-mindedness, with its safeguards against the loss of true belief, unlike vices like dogmatism, is truth-conducive beyond selective contexts and across a variety of situations, "under both hospitable and inhospitable environments, and regardless of whether her beliefs are antecedently true or false" (Ibid.).

Kwong is right to insist on fuller and richer notions of open-mindedness, and he does well to highlight arguments that proceed from overly narrow and impoverished accounts of open-mindedness. But even if the richer accounts he presents are correct, does it follow that open-mindedness is truth-conducive, as he humility amount to, as is the question of the extent to which they overlap or otherwise relate to one another. Thank you to the referee for pointing out this connection.

${ }^{5}$ Wayne Riggs is an example of someone who develops this sort of rich notion of open-mindedness. Riggs argues that genuine open-mindedness requires that one takes challenges to ones own views seriously, and that doing so requires both self-knowledge and self-monitoring. Self-knowledge is required to know things like what one's biases are, and what intellectual bad habits and weaknesses one has, etc. Self-knowledge is also required to know in what sorts of domains these distorting factors tend to operate. On Riggs' view, self-monitoring is then required to put this self-knowledge into practice, by indentifying if one is in circumstances where one's intellectual weaknesses tend to lead one astray. For a development of this account of open-mindedness, see Riggs (2010). 
claims? If a subject is well-justified thinking her beliefs are true, and is correct in thinking that they have not been tainted by bad habits of thought, and / or if she has no reason to think that questioning them is helpful for reaching the truth, does that mean that her beliefs are more likely to be true than false? It does not. This only follows on the assumption that the environment is epistemically hospitable, including at least in the sense that things are more or less as they appear.

The most that follows from Kwong's arguments is that genuine openmindedness is epistemic rationality-conducive, or perhaps epistemic rationalitypreserving. Someone who reviews and assesses the evidence, examines the context under which the beliefs were acquired, etc. is likely to end up with epistemically rational or reasonable beliefs, and if their beliefs are already rational and reasonable, such habits will make it more likely that defeaters are defeated, and epistemic rationality will be preserved across time. But epistemic rationality is non-factive: one can be rational in believing falsehoods. Unless the environment is favourable, these rational beliefs will not in addition be true.

But now one might wonder: if a person may be in such an epistemically unfriendly environment that their exercise of open-mindedness nets them all false beliefs, would the person actually acquire epistemically rational beliefs? After all, they would not acquire understanding at all, since understanding is factive: you cannot understand something that is false ${ }^{6}$.

It is true that in such environments the subject would not have understanding or knowledge, or any other positive epistemic standing that entails truth. But that is no reason to doubt that they could still nevertheless enjoy epistemically rational

\footnotetext{
${ }^{6}$ Thank you to an anonymous referee for raising this issue.
} 
beliefs. Neither knowledge nor understanding is necessary for having epistemically rational or justified beliefs. For example, a subject in a Gettier case (by definition) has a rational or justified belief, despite lacking knowledge or understanding of the target proposition. And rational or justified false beliefs are commonplace, for example when one forms a false belief on the false testimony of others. When a seemingly reliable and trustworthy person tells you something and you believe what they say, you thereby form a rational or justified belief. If that belief happens to be false, you cannot know or understand the proposition, but that is no bar to its being rationally held. One can rationally believe falsehoods. Unless the environment is favourable, these rational beliefs will not in addition be true.

To illustrate all this, consider the following example. Suppose that Alys is learning the Welsh language, and she wonders if the language is spoken natively in any communities outside of Wales. Suppose that her mischievous Welsh teacher tells her that no communities outside of Wales, other than perhaps a few exceptions on the English/Welsh border, natively speak Welsh. Given what she takes to be authoritative testimony from her teacher, she would thereby form the perfectly reasonable and rational belief that no communities natively speak Welsh outside of the UK. While her belief would be perfectly reasonable, it would be false: Welsh is natively spoken in Y Wladfa, the Welsh colony in Patagonia.

Suppose that Alys is an open-minded, non-dogmatic individual. Here she is reasonable in thinking that her belief is true, and she is correct in thinking that it has not been tainted by bad habits of thought. After all, she believes something about the Welsh language on the basis of testimony from her Welsh teacher, which is a perfectly reasonable way of forming beliefs about Welsh, free from prejudice or bias. Having accepted the say-so of her teacher on something that the teacher ought to 
know, in what seem perfectly ordinary circumstances, she has no reason to think that questioning her belief is helpful for reaching the truth. Despite all this, it does not follow that her belief is more likely to be true than false. Nor does it follow that if she continues to be open-minded, she is any more likely to come to believe truly than falsely. That still only follows on the assumption that the environment is epistemically hospitable.

If Alys has the bad luck of being surrounded by possible sources of error, with no one or nothing to correct her belief, she will continue to believe falsely, albeit rationally. And there is nothing peculiar about this particular belief. What is so for her belief about Welsh generalizes to all her other beliefs. If the environment is extremely epistemically inhospitable, she is no more likely to acquire and retain true beliefs over false ones in virtue of her open-mindedness, although rational and reasonable beliefs will be acquired and retained. If open-mindedness is truthconducive, that is highly contingent, conditional upon things like what a person already believes, or how hospitable the epistemic environment is. Kwong's stated aim is to show that open-mindedness is actually truth-conducive, and truth-conducive without qualification. But it is hard to see how anything about truth-conduciveness itself follows from the considerations advanced.

Darrell Rowbottom makes a related point when considering if a "critical attitude", or adopting critical procedures, a hallmark of Karl Popper's Critical Rationalism, is truth-conducive (Rowbottom, 2011, p. 23). Rowbottom notes that adopting a critical attitude might help one find inconsistencies in what one believes, and given that one knows that inconsistent beliefs cannot all be true, by adopting critical procedures one is able to rule out some false beliefs. In this way a critical attitude might, among other things, be conducive to the modest goal of avoiding some 
falsities. But for all that, one falsity may be replaced with another. Crucially, avoiding some falsities need not minimize falsity, and truth-conduciveness is a matter of both minimizing falsity and maximizing truth (Ibid.).

In response to the Alys case, perhaps one might have a broader notion of truthconduciveness in mind than the one I assume, one that considers overall truthconduciveness ${ }^{7}$. One might think that we need to look at "the life" of the trait, to see whether it leads to more truths than not over time. Even if Alys' epistemic environment is such that she ends up with a false belief regarding which people speak Welsh for the rest of her life, has the exercise of open-mindedness helped her gain other true beliefs in further domains in a more favorable ratio than false beliefs? If so, then maybe open-mindedness is truth-conducive.

While the Alys case focuses on her one belief about which people speak Welsh, as noted above, there is nothing special about this particular belief: what is so for her belief about Welsh, could be true for all of her beliefs, whatever their domain. If Alys has the very bad luck of being surrounded by possible sources of error, with no one or nothing to correct her belief, she will continue to believe falsely, albeit rationally. What Montmarquet's objection below will make salient is that if the environment is extremely epistemically inhospitable, Alys is overall no more likely to acquire and retain true beliefs over false ones in virtue of her open-mindedness, although rational and reasonable beliefs will be acquired and retained.

While open-mindedness may have benefits over time by helping us retain true beliefs, by providing opportunities for us to review evidence, etc., this is at most highly contingent. Whether open-mindedness is more truth-conducive overall than all the traits available to us, including the putative vices of gullibility and dogmatism,

\footnotetext{
${ }^{7}$ Thank you to an anonymous referee for this suggestion.
} 
depends on, among other things, what environment we find ourselves in. One might think that open-mindedness may have the benefit of forcing a person to pursue further inquiries regarding their beliefs, perhaps even to the point where they might be able to discover that their environment is epistemically unfriendly. Perhaps in some environments open-mindedness could have this result, but as we shall see below, there is nothing in open-mindedness itself that makes this truth-conduciveness any more likely. If open-mindedness is truth-conducive, that remains highly contingent, conditional upon things like what a person already believes, or how hospitable the epistemic environment is.

The moral here is that although Kwong is right to clarify what genuine openmindedness consists in, he does not consider sufficiently epistemically unfriendly environments that would be needed to show that open-mindedness is indeed truthconducive. It seems that even if one exercises maximally good habits of mind, it is still possible that ones beliefs could be false, and remain false, even when retained in maximally virtuous ways. Whether the beliefs are formed and maintained in ways that are in fact true still depends on the extent to which the subject's environment is epistemically friendly. We have so far been given no reason to think that genuine open-mindedness will ensure that an actually favourable ratio of true over false beliefs will be generated.

All this highlights the significance of an objection to the claim that openmindedness is conducive to truth, and that truth-conduciveness is what makes a given trait an intellectual virtue. Kwong notes this objection in a footnote, but somewhat surprisingly given the unqualified conclusions he argues for, he does not respond to it (Kwong, 2017, p. 1615, footnote 3). Instead, he says in passing that he finds Linda Zagzebski's responses to the argument quite convincing (Ibid). I shall now outline 
this argument, and contend that Zagzebski's responses to it are inadequate. If I am right, we are left with the original problem Kwong sought to address: it is contingent if open-mindedness is truth-conducive, and if a necessary tie to truth is what makes an intellectual virtue a virtue, then the status of open-mindedness as an intellectual virtue is jeopardised.

\section{The Undiscussed Challenge to Open-mindedness and Truth: Montmarquet's}

\section{Objection and Zagzebski's Reply:}

\section{Montmarquet's Objection}

Besides the two kinds of arguments Kwong discusses, why else might one think that truth-conduciveness is not necessary for a trait to be a virtue? James Montmarquet has aimed to show this with a version of the New Evil Demon problem, but here targeting the relation between the virtues and truth, rather than the relation between epistemic justification and $\operatorname{truth}^{8}$. Montmarquet writes,

Let us assume that a Cartesian 'evil demon' has, unbeknownst to us, made our world such that truth is best attained by thoroughly exemplifying what, on our best crafted accounts, qualify as intellectual vices. Presumably, we would not therefore conclude that these apparent vices are and have always been virtues. (Montmarquet, 1987, p. 482)

By way of illustration, consider Montmarquet's case of Galileo and his lazy, intellectually uncurious brother Schmalileo. Ordinarily, we have no hesitation in correctly noting that Galileo is a person of intellectual virtue, and his brother is one of intellectual vice. But suppose further that an evil demon sees to it that Galileo's open-mindedness, insight, intellectual courage, and so on result in false beliefs, whereas Schmalileo's dogmatism, gullibility, and intellectual laziness always results

\footnotetext{
${ }^{8}$ The traditional New Evil Demon problem specifically targeted process reliabilism, and in particular challenges the claim that reliability is necessary for epistemic justification. That New Evil Demon problem was introduced into the literature by Lehrer and Cohen (1983); Cohen (1984).
} 
in true beliefs. Does this make any difference to who possess intellectual virtues, and to what extent? Should we say that Galileo is intellectually vicious, and Schmalileo is the one who possesses and exercises intellectual virtue? That would be absurd.

Intuitively, Galileo is the intellectually virtuous one, and his brother the intellectually vicious one, and this remains unaffected by whether the demon is manipulating the truth-conduciveness of their belief forming processes. The argument concludes, therefore, that truth-conduciveness is not necessary for a trait to be a virtue. As I noted above, Kwong explicitly avoids this argument, and what he does say does not generalize to it ${ }^{9}$. Instead, he claims that Linda Zagzebski's response to it is one that he agrees with (Kwong, 2017, p. 1615, footnote 3). So I shall now outline and evaluate Zagzebski's reply.

\section{Zagzebski's Reply:}

In response to Montmarquet's objection, Zagzebski writes,

Of course, the prevailing belief in the truth conduciveness of, for example, open-mindedness, intellectual courage, and intellectual sobriety (carefulness, attentiveness, thoroughness) is not a demonstration that these virtues are truth-conducive, but is it not the case that we only consider these traits virtues because we take them to be truth-conducive, or knowledge conducive in some other way? (original emphasis) (Zagzebski, 1996, p. 185)

One can concede for the sake of argument that Zagzebski is correct: suppose that we consider traits to be virtues because we take them to be truth-conducive; and if we had reason to think that a trait was not truth-conducive, we would no longer consider it to be a virtue. What follows from this? Nothing about whether

\footnotetext{
${ }^{9}$ An anonymous referee suggested that Kwong does not, as far as they can see, intend his ways of handling recent objections raised by Carter and Gordon, Levy, and Cohen to resolve Montmarquet's objection. This may be correct. I mean only to say that, intended by Kwong or not, what he does say does not give reliabilists the resources to reply to Montmarquet's objection. If reliabilists can resolve this problem, they must look elsewhere for a solution. The referee also noted that we do not know why Kwong thinks Zagzebski's responses are adequate in resolving Montmarquet's objection. This is true: since we do not know Kwong's reasons, the best we can do is examine Zagzebski's reply, and determine if it is sufficient to block Montmarquet's objection. This leaves open the possibility that Kwong might reply differently to the objection.
} 
intellectual virtues must actually be truth-conducive; we are still only left with the point that we might have to believe traits to be virtues because of our beliefs about their truth-conduciveness.

Zagzebski continues:

So if it turned out that we were wrong about the truth-conduciveness of one of these traits, that trait would cease to be considered an intellectual virtue. What we would not do is to continue to treat it as an intellectual virtue and then go on to declare that intellectual virtues are not necessarily truth-conducive. I suggest, then, that any evidence of an intellectual virtue that is not truth-conducive (or knowledge conducive) is more reasonably interpreted as evidence that that such a trait is not a virtue than as evidence that some intellectual virtues are not truth-conducive. (emphasis added) (Ibid.)

The heart of Zagzebski's reply is that if we found evidence against the truthconduciveness of a trait, we would no longer consider that trait a virtue. Let us also grant that for the sake of argument. What follows from this as a reply to Montmarquet's objection, and in particular for the thesis that the virtues must be truth-conducive?

Suppose we get evidence that a trait is not truth-conducive. Let us also for the sake of argument grant that we will not from now on consider it a virtue. Even this does not settle the question of whether the trait was a virtue before this evidence was discovered, and whether it is a virtue because the trait was actually truth-conducive. Take a paradigm example of someone of intellectual virtue: she is someone who is open-minded, intellectually courageous, insightful and so on. Now suppose that we get evidence on her deathbed that these traits are not truth-conducive, and in fact, these traits resulted in the person forming systematically false beliefs her whole life. Even though we might not count these as virtues from now on, does it follow that until that point the person led a life of intellectual vice? No. I submit that the evil demon style thought experiment just makes vivid that this point about the virtues holds not only for individual agents and individual traits. Rather, it is true of all us, 
and for the virtues in general -- humans can possess intellectual excellences, regardless of whether or not the traits in question are actually truth conducive.

As we have seen, the crux of Zagzebski's reply is that if we found evidence against the truth-conduciveness of a trait, we would no longer consider that trait a virtue. But what is curious is why in general, and why by reliabilist lights in particular, would not considering a trait to be a virtue in those circumstances mean that it is not one? Surely we should allow for the possibility that we are fallible and indeed mistaken about which particular traits are virtues and which are vices. For example, suppose that we had misleading evidence that open-mindedness is not truthconducive. Zagzebski might be right that we might from then on not consider it to be a virtue. But the evidence is misleading. Surely everyone, including the reliabilist, should be open to the possibility that the trait is a virtue nonetheless.

Similarly, suppose misleading evidence arose that dogmatism and gullibility are truth-conducive. Perhaps we might from then on consider these traits to be virtues. Does it follow that they are? Or should we allow that we might just be mistaken about whether these traits are virtues or vices? If these are coherent questions, then this casts doubt on Zagzebski's claim that reactions to discovered evidence and beliefs about truth-conduciveness are enough to settle the question of what makes a virtue a virtue. The remaining question is this: why in general should what we would consider virtues, if presented with evidence of their un/reliability, be probative in showing that de facto reliability is necessary for a trait being a virtue?

So on the one hand we have Montmarquet's intuitive argument of the possibility of virtues without reliability, and on the other, we have Zagzebski's reply, which is off point. The question is if reliability and truth-conduciveness are necessary 
for virtue. But Zagzebski's reply is cast in terms of whether we must believe that reliability is necessary for virtue, or if being presented with counterevidence of unreliability should make us then think that certain traits are virtues or vices. Even if Zagzebski's points are granted, nothing follows about whether reliability itself (rather than beliefs about it) is necessary for a trait to count as a virtue. So Montmarquet's objection stands.

\section{Concluding Remarks:}

Kwong's arguments are good as far as they go, and they advance the debate by usefully clarifying ways in how best to understand the nature of open-mindedness. But his arguments do not establish the desired conclusions that open-mindedness is truth-conducive, and that it is a virtue because it is truth-conducive. To establish these much stronger conclusions we need an adequate reply to Montmarquet's objection, and in his paper no reply is given. Perhaps there is a way for Kwong and other reliabilists to respond to Montmarquet's objection, but I hope to have made the case that the onus of offering such a response rests with them. I have argued that Zagzebski's reply, to which Kwong defers, is inadequate, since her conclusions about reliability are not supported by her premises that only involve beliefs and evidence about reliability.

So we are left in this position: given the possibility of a New Evil Demon style scenario for the virtues, open-mindedness is at best contingently truth-conducive, truth-conducive with qualification. That is, the virtues are at most truth-conducive if everything is in some sense normal, and if things are as they appear, which is at odds with the reliabilist explanation of character traits being intellectual virtues because of a robust connection with truth. We have now returned to where Kwong began: we 
either need an adequate reliabilist response to Montmarquet's objection, or else seek alternative accounts of what it is that makes a virtue a virtue.

What are the alternatives? The other main existing alternative to the question of what makes a virtue a virtue is known as virtue responsibilism. Perhaps reflecting on this kind of New Evil Demon problem for virtue reliabilism would lead one to conclude that the virtues need not be truth-conducive (and that the vices are not intellectual defects because they reliably lead to falsehood). According to the virtue responsibilist, what makes a trait a virtue is not that it is truth-conducive, but rather, that it is accompanied by the right sort of motivation (e.g. Baehr 2011; Montmarquet 1993). Battaly writes, “According to Montmarquet, the primary intellectual virtue, conscientiousness, is constituted by the motivation to attain truth and avoid falsehood. A person is conscientious when she is 'trying...to arrive at the truth and to avoid error'(21)" (original emphasis) (Battaly, 2008, p. 648).

While very different from virtue-reliabilism, notice that here too it is a highly contingent matter whether a particular person's possessing a given character trait is accompanied by particular motivations. So is being suitably motivated necessary for a given trait to be a virtue? Briefly, here is a prima facie reason to think not. Compare two subjects: both hold their beliefs critically, open to the possibility that they might be mistaken, and give due weight to any counter-evidence should they come across it, etc. It seems that both subjects are open-minded. Now suppose that one subject, but not the other, is also trying to believe what is true and not believe what is false. The other subject is not trying to do the opposite - suppose only that they lack any relevant motivation either way. Is it correct to hold that in one subject open-mindedness is a virtue, and in the other it is not? That seems wrong. 
Why is the person who lacks the relevant motivation, but possesses all the other dispositions that make up open-mindedness, nevertheless still virtuous? Arguably for a character trait to be a virtue, having it should contribute to making its possessor a good person. So in the case of the intellectual virtues, having them should contribute to making one an intellectually good person ${ }^{10}$. And it seems that the subject who holds his beliefs critically, is open to the possibility that he might be mistaken, and gives due weight to any counter-evidence should he come across it etc., is an intellectually good person in virtue of having these dispositions. Possessing these dispositions improves their intellectual character. At the very least, the subject is intellectually better off than they would be, if they did not possess these dispositions. That the person can be praised for having the dispositions that make up open-mindedness, even while lacking the relevant motivation, is some evidence that the trait is nevertheless still a virtue.

So while the suitably motivated person might be even more virtuous than the other, it seems too demanding to say that the subject who lacks the truth-seeking motivation is devoid of virtue, despite exemplifying all the other aspects of mind that make up open-mindedness. If this is correct, then having the right sort of motivation is not necessary for a trait to be a virtue. Presumably then too, a vice would be vice, regardless of whether or not the subject had negative motivations.

What if, despite their differences, both reliabilist and responsibilist virtue theories are in inadequate for the same reason? Namely, both make it a highly contingent matter which character traits are intellectual virtues and vices. But given

\footnotetext{
${ }^{10}$ For the suggestion linking a character trait being a virtue with its thereby being a good making feature of the person who possesses it, see Whitcomb et al., 2017, p. 12. For discussion of the idea that for a character trait to be a virtue, the motivations that underlie it must make its possessor a good person, see Baehr (2011), ch. 6; Battaly (2015), ch. 3 .
} 
Montmarquet's objection, it is worth exploring the hypothesis that, given the kind of beings we are, it is necessary that certain traits are virtues or vices. Exploring such a possibility, however, must await another occasion ${ }^{11}$.

\section{Sources Cited:}

Baehr, Jason. (2011) The Inquiring Mind. Oxford: Oxford University Press.

Battaly, Heather. (2008) "Virtue Epistemology". Philosophy Compass 3/4: 639-663.

Battaly, Heather. (2015) Virtue. Malden, MA: Polity Press.

Becker, Kelly. (2008) “Epistemic Luck and The Generality Problem”. Philosophical Studies 139: 353-366.

Beebe, James. (2004) “The Generality Problem, Statistical Relevance, and the TriLevel Hypothesis". Nous 38: 177-195.

Carter, J. Adam \& Gordon, Emma C. (2014) “Openmindedness and Truth”.

Canadian Journal of Philosophy 44: 207-224.

Cassam, Quassim. (2016) "Vice Epistemology". The Monist 99: 159-180.

Cohen, Stewart. (1984) “Justification and Truth". Philosophical Studies 46: 279295.

Comesana, Juan. (2002) "The Diagonal and the Demon." Philosophical Studies 110: 249-66.

Comesana, Juan. (2006) "A Well-Founded Solution to the Generality Problem". Philosophical Studies 129: 27-47.

Conee, Earl and Feldman, Richard. (1998) "The Generality Problem for Reliabilism”. Philosophical Studies 89: 1-29.

Goldman, Alvin. (1979) “What Is Justified Belief” in Pappas, G. ed. Justification and Knowledge. Dordrecht, Holland: D. Reidel.

\footnotetext{
${ }^{11}$ Thanks to audiences at Lingnan University, Hong Kong, and the Bled Epistemology Conference, Slovenia. Thanks also to two anonymous referees for Synthese, and especially Rhiannon James for helpful discussion and written comments on earlier drafts of this paper.
} 
Goldman, Alvin. (1986) Epistemology and Cognition. Cambridge, Mass.:

Harvard University Press.

Greco, John. (2010) Achieving Knowledge. Cambridge: Cambridge University Press.

Heller, M. (1995) "The Simple Solution to the Problem of Generality". Nous 29: $501-515$.

Kwong, Jack M.C. (2017) “Is Open-Mindedness Conducive to Truth?”. Synthese 194: $1613-1626$.

Lehrer, Keith and Cohen, Stewart. (1983) 'Justification, Truth, and Coherence'. Synthese 55: 191-207.

Montmarquet, James. (1987) “Epistemic Virtue”. MIND 96: 482-497.

Riggs, Wayne. (2010) “Open-Mindedness”. Metaphilosophy 41: 172-188.

Rowbottom, Darrell P. (2011) Popper's Critical Rationalism: A Philosophical Investigation. New York: Routledge.

Montmarquet, James. (1993) Epistemic Virtue and Doxastic Responsibility. Roman and Littlefield.

Sosa, Ernest. (1980) "The Raft and the Pyramid: Coherence versus Foundations in the Theory of Knowledge". Midwest Studies in Philosophy 5: 3-25.

Sosa, Ernest. (1991) Knowledge in Perspective. Cambridge: Cambridge University Press.

Sosa, Ernest. (2007) A Virtue Epistemology. Oxford: Oxford University Press.

Sturgeon, Scott. (2000) Matters of Mind. London: Routledge.

Whitcomb, D., Battaly, H., Baehr, J., Howard-Snyder, D. (2017) “Intellectual Humility: Owning Our Limitations”. Philosophy and Phenomenological Research 94: 509-539.

Zagzebski, Linda. (1996) Virtues of the Mind. Cambridge: Cambridge University Press. 